\title{
Are Laws of Domestic Violence and Rehabilitation of Substance Abusers Satisfactory in Sri Lanka? A Review with Cases
}

Ariyarathna D*, Hulathduwa SR

Department of Forensic Medicine, Faculty of Medical Sciences, University of Sri Jayewardenepura, Sri Lanka

\begin{abstract}
The following two cases are representative examples to prove that existing legal framework assists in the rehabilitation of the accused even though it is one of the standard yet 'rather difficult to achieve' type of objectives of penalty/punishment. New laws are implemented to fit the changing expectations of the society. Two such examples are the Prevention of Domestic Violence Act (No.34 of 2005) and Drug Dependent Persons (Treatment and Rehabilitation) Act (No. 54 of 2007). Unlike judicial medical officers who closely liaise with the judiciary, other clinicians are seldom aware of the rehabilitative strategies mandated by recent changes in law such as the two above mentioned acts. Case 01 is related to persistent domestic violence where the proper and timely implementation of law has resulted in the positive behavioural change of the male partner to the utmost benefit of the whole family. Case 02 refers to a young male who was severely addicted to heroin where compulsory rehabilitation imposed by the courts had changed him back to normal. The authors' intension is to make the clinicians and relevant stakeholders aware of the existing legal provisions they can utilize as a part and parcel of their treatment and follow-up regimes.
\end{abstract}

Keywords: Domestic violence, Rehabilitation, Substance abuse

Received: 02 Nov 2019, Revised version accepted: 30 Dec 2019, Published: 31 Dec 2019. *Corresponding author: Ariyarathna D, $\triangle$ Email: ariyaratna@sjp.ac.lk, (iD https://orcid.org/0000-0002-4266-5508

Cite this article as: Ariyarathna D, Hulathduwa SR. Are Laws of Domestic Violence And Rehabilitation of Substance Abusers Satisfactory in Sri Lanka? A Review with Cases. Medico-Legal Journal of Sri Lanka, 2019;7(2):73-75.

DOI: http://doi.org/10.4038/mljsl.v7i2.7396

Copyright: @ 2019 with the Medico-legal Journal of Sri Lanka.

This is an open-access article distributed under the terms of the Creative Commons Attribution 4.0 International License, which permits unrestricted use, distribution and reproduction in any medium provided the original author and source are credited.

\section{Introduction}

Laws are implemented to achieve social control through regulating human behaviour. This ensures safety, dignity and an atmosphere to entertain our rights and privileges. Most criminal laws have a punitive function. They control human behaviour by pain of punishment. Changing expectations have changed the objectives of some laws where rehabilitation has been introduced as a mandate. Prevention of Domestic Violence Act (No. 34 of 2005) ${ }^{[1,2]}$ and Drug Dependent Persons (Treatment and Rehabilitation) Act, (No. 54 of 2007) ${ }^{[3]}$ are some examples. Once the behavior of a person is deranged he becomes incapable of behaving as a reasonable person in the society. There are multiple approaches and measures implemented in a civilized society to take him back to the expected caliber. One such entity is the law of a country. Human behaviour is governed by many factors including socio-economic background, situational needs, culture, morality, education, upbringing and genetic context. When a person's overall behaviour in the society cannot be effectively controlled by customary means such as social norms, values, religious constrains and cultural influence, the law of the country plays a crucial, distinct, specific and determinant role in establishing social control and security as well as the welfare of the individual himself who shows a "deranged" behaviour. ${ }^{[4]}$ The authors wish to highlight this with two case examples to elaborate the "rehabilitative approach" of the criminal justice system in Sri Lanka.

\section{Case reports}

Case 1: A 43-year-old female had been examined for multiple injuries on the body including a periorbital haematoma, contusions on upper arms and generalized aches and pains following assault by her husband. History revealed chronic (ongoing) episode of 
physical domestic violence. With the ongoing abuse the police had filed a case at the magistrate court. After the fact reporting by the Police, an interim order and a protection order had been issued. While the court case was going on mandatory family counselling for the husband and wife was ordered by the courts. It was revealed later through the police, that with time the husband became less violent and empathetic about the family. Review revealed that the family was stable after the court case under the act of Prevention of Domestic Violence. The examinee also emphasized how it helped to prevent the passive abuse of children as well.

Case 2: A 25-year-old male with alleged abuse of heroin was produced before us for medico-legal examination. History and clinical examination confirmed that he was a chronic drug addict. Detailed history and psychiatric assessment revealed the dependence features. The authors had prepared the report to the magistrate indicating the dire need of rehabilitation. With the details made available to us during history taking, the family of the victim was contacted several months later to learn that he was successfully rehabilitated at the government expense and later had been sent abroad as an unskilled labourer. They further claimed that he now regularly sends money home to care for the aged parents and two school-going siblings.

\section{Discussion}

At times it is difficult to gather adequate information through qualitative research on certain medical matters. In such situations case studies are an accepted way to overcome difficulties. ${ }^{[5]}$ The authors are of the view that the awareness among the health care personnel related to relatively newly implemented laws on domestic violence and the rehabilitation of drug addicts is relatively unsatisfactory. In day today practice judicial medical officers examine victims and assailants of a wide array of cases including sexual offences, domestic violence, child abuse, drug intoxication and so on. Apart from medico-legal obligations, they rarely get an opportunity to take part in preventive or rehabilitative measures. One of the recent advances of the criminal justice system is the implementation of laws mainly focused on preventive aspects including rehabilitation. Rehabilitation has been recognized instead of punishment as a global trend. ${ }^{[6,7,8]}$
It is a known fact in penology that punishment has limited benefits. ${ }^{[9,10]}$ Other alternative strategies such as rehabilitation may have an enormous short term and long term benefit to the individual, immediate family and to the society at large. Punishment or penalty is a temporary answer though rehabilitation is a long lasting remedy.

Prevention of Domestic Violence Act contains many positive aspects. It recognizes the emotional abuse, provides room for quick intervention and counseling. There are few negative aspects as well. It may empower a woman to implement legal actions against her own husband on bogus grounds. Overt actions taken by women may destabilize the social and cultural bonds of the conventional family. The permanent order is given for only one year period during which time the parties should settle the matter in a positive manner. With the risk of further abuse, the order could be extended for one more year. Not only the spouses, but also the parents and in-laws too are under the protection of the act under the preview of "domestic violence".

Under the Drug Dependent Persons (Treatment and Rehabilitation) Act, No. 54 of 2007, there are several well established centres in Sri Lanka in order to rehabilitate the drug-dependents. Such centers are governed under the supervision of the National Dangerous Drug Control board of Sri Lanka with welltrained counsellors. [11] The desired period of residential treatment is three months with well scrutinized programmes to rehabilitate the victim which is the essential part in the long run to minimize drug-related offences rather than blindly incarceration of the victims. The residential period is followed by essential relapse-prevention programme. During this time the family support of the victim is expected to prevent him from going back to his addictive behaviours. [11]

\section{Conclusion and recommendation}

Laws help to maintain social harmony and peace. Most criminal laws aim at punishment. In cases of drug dependency punishment alone may not be effective at all. The dependency being the result of chemical nature of the drug, the offender being the victim himself, such individuals may need rehabilitation, treatment for withdrawal and re-socialization. Imminent threats to lives of family members and recurrent abuse could be prevented by legal provisions in the Domestic Violence Act. An increased awareness 
of these laws would help clinicians and lay people further extend their assistance to aggrieved patients and family members respectively.

\section{Disclosure statement}

Conflicts of interests: The authors declare that they have no conflicts of interests.

Funding: None

\section{References}

1. Preventionof Domestic Violence Act, No. 34 of 2005.Available at: http://www.childprotection.gov.lk/Child_Related _ACTs/Prevention\%20of\%20Domestic\%20Viol ence\%20Act,\%20No.\%2034\%20of\%202005.pdf . [Accessed on 2019 Nov.30.]

2. Tegal M. How effective is the Domestic Violence Act?. [Accessed on 2019 Nov.30].

Available at: http://www.dailymirror.lk/105882/HowEffective-is-the-Domestic-Violence-Act.

3. Reardon S. Drug - free therapy makes addicts 'forget' addiction. New Scientist [Internet]. 2012Apr21 [cited 2019Dec15];214(2861):17. Available from: https://www.newscientist.com/article/dn21701drug-free-therapy-makes-addicts-forgetaddiction/. DOI: 10.1126/science. 1215070

4. DrugDependent Persons (Treatmentand Rehabilitation) Act, No. 54 OF 2007. [Accessed on 2019 Nov.30.] Available at: http://www.nddcb.gov.lk/Docs/acts/English.pdf

5. Wilson JQ. Crime and public policy [Internet]. Oxford: Oxford University Press; 2011 [cited 2019Nov30]. Available from: https://www.oxfordhandbooks.com/view/10.109 3/oxfordhb/9780195398823.001.0001/oxfordhb9780195398823-e-1

6. Nissen T, Wynn R. The clinical case report: a review of its merits and limitations. BMC Research Notes. 2014;7(1). 10.1186/1756-05007-264

7. Meijer S. Rehabilitation as a positive obligation. European Journal of Crime, Criminal Law and Criminal Justice. 2017 Mar 1;25(2):145162. https://doi.org/10.1163/15718174-25022110

8. Alschuler AW. The Changing Purposes of Criminal Punishment: A Retrospective on the past Century and Some Thoughts about the Next. The University of Chicago Law Review [Internet]. 2003;70(1):1-22Available from: https://chicagounbound.uchicago.edu/cgi/viewco ntent.cgi article $=1893 \&$ context=journal_articles

9. Martz W. A Comparative and Analytical Essay Sri Lankan and American Drug Policy: The Island [Internet]. 2016Oct22 [cited 2019Dec15]; Available from: https://www.island.lk/index.php?page_cat=articl e-details \&page $=$ articledetails\&code_title $=154233$

10. Chandler RK, Fletcher BW, Volkow ND. Treating Drug Abuse and Addiction in the Criminal Justice System. Jama [Internet]. 2009;301(2):183-190 Available from: https://www.ncbi.nlm.nih.gov/pmc/articles/PMC 2681083/. doi: 10.1001/jama.2008.976

11. National Drug Control Board. [homepage on the Internet]. [updated 2015; cited 2019Nov30]. Treatment Programme. Available from: http://www.nddcb.gov.lk/treatment.html 